Mycologia, 98(6), 2006, pp. 896-905.

(C) 2006 by The Mycological Society of America, Lawrence, KS 66044-8897

\title{
An overview of the higher level classification of Pucciniomycotina based on combined analyses of nuclear large and small subunit rDNA sequences
}

M. Catherine Aime ${ }^{1}$

USDA-ARS, Systematic Botany and Mycology Lab, Beltsville, Maryland 20705

P. Brandon Matheny Biology Department, Clark University, Worcester, Massachusetts 01610

Daniel A. Henk USDA-ARS, Systematic Botany and Mycology Lab, Beltsville, Maryland 20705

Elizabeth M. Frieders

Department of Biology, University of Wisconsin, Platteville, Wisconsin 53818

R. Henrik Nilsson Göteborg University, Department of Plant and Environmental Sciences, Göteborg, Sweden

Meike Piepenbring J.W. Goethe-Universität Frankfurt, Department of Mycology, Frankfurt, Germany

David J. McLaughlin

Department of Plant Biology, University of Minnesota, St Paul, Minnesota 55108

Les J. Szabo USDA-ARS, Cereal Disease Lab, University of Minnesota, St Paul, Minnesota 55108

Dominik Begerow Universität Tübingen, Spezielle Botanik und Mykologie, Tübingen, Germany

José Paulo Sampaio CREM, SABT, Faculdade de Ciências e Tecnologia, Universidade Nova de Lisboa, 2829-516 Caparica, Portugal

Robert Bauer

Michael Weiß

Franz Oberwinkler Universität Tübingen, Spezielle Botanik und Mykologie, Tübingen, Germany

David Hibbett

Biology Department, Clark University, Worcester, Massachusetts 01610

Abstract: In this study we provide a phylogenetically based introduction to the classes and orders of Pucciniomycotina (=Urediniomycetes), one of three

Acepted for publication 7 September 2006.

${ }^{1}$ Corresponding author. E-mail: cathie@nt.ars-grin.gov subphyla of Basidiomycota. More than 8000 species of Pucciniomycotina have been described including putative saprotrophs and parasites of plants, animals and fungi. The overwhelming majority of these $(\sim 90 \%)$ belong to a single order of obligate plant pathogens, the Pucciniales (=Uredinales), or rust fungi. We have assembled a dataset of previously published and newly generated sequence data from two nuclear rDNA genes (large subunit and small subunit) including exemplars from all known major groups in order to test hypotheses about evolutionary relationships among the Pucciniomycotina. The utility of combining nuc-lsu sequences spanning the entire D1-D3 region with complete nuc-ssu sequences for resolution and support of nodes is discussed. Our study confirms Pucciniomycotina as a monophyletic group of Basidiomycota. In total our results support eight major clades ranked as classes (Agaricostilbomycetes, Atractiellomycetes, Classiculomycetes, Cryptomycocolacomycetes, Cystobasidiomycetes, Microbotryomycetes, Mixiomycetes and Pucciniomycetes) and 18 orders.

Key words: basidiomycetes, molecular phylogenetics, parasitic fungi, rDNA systematics, Urediniomycetes

\section{INTRODUCTION}

One-third of described Basidiomycota belong to subphylum Pucciniomycotina (=Urediniomycetes sensu Swann and Taylor 1995). Roughly 7000 of these, or $\sim 90 \%$, belong to a single order, Pucciniales (=Uredinales G. Winter) or the rust fungi (Kirk et al 2001). The remaining fungi within the Pucciniomycotina are remarkably diverse ecologically, biologically and physiologically; only with the relatively recent advent of ultrastructure, biochemical and molecular systematic studies have the relatedness of the varied fungi now placed in the Pucciniomycotina become apparent. These include Microbotryales, phytopathogens once classified in the Ustilaginomycotina (true smuts and relatives, Ustilaginomycetes sensu Bauer et al 2001); numerous basidiomycetous yeasts formerly allied with Auriculariales and other groups of Agaricomycotina (mushroom-forming fungi and related taxa; Hymenomycetes sensu Swann and Taylor 1993); and at least one species, Mixia osmundae, formerly classified within the Ascomycota (Nishida et al 1995). 
Most species of Pucciniomycotina are parasitic and the group includes phytopathogens (e.g. Pucciniales, Microbotryales), mycoparasites (e.g. Tuberculina, Spiculogloea) and entomopathogens (e.g. Septobasidiales). A few are putatively saprotrophic or are of unknown trophic habit. Pucciniomycotina species are present in most habitats including freshwater (Bauer et al 2003) and marine environments (Swann et al 2001). Dimorphism, cryptic fructifications, heteroecism and multiple spore types all have evolved in at least some lineages of Pucciniomycotina, hampering the collection of complete biological and life cycle data for many taxa. Yet species of Pucciniomycotina are causal agents of some of the most devastating diseases of crops, may cause opportunistic disease in humans and have shown potential as biological control organisms of invasive plants and of other pathogenic fungi (e.g. Evans 1993, Swann et al 2001).

A few Pucciniomycotina species produce basidiocarps, these typically being simple stipitate-capitate (stilboid) or resupinate (FIG. 1b) structures. Some Pucciniomycotina species form hyphae (filamentous) or yeasts or both (dimorphic) (FIG. 1d). Members of the Pucciniales produce spore-filled fruiting structures termed sori (FIG. 1f). Basidia of teleomorphic species may take the form of teliospores, holobasidia or phragmobasidia, and basidiospores may be sessile, gasteroid or forcibly discharged. The Pucciniomycotina is distinguished from the other two major clades of Basidiomycota by the possession of simple septal pores that lack membrane-bound caps (Swann et al 2001, Weiß et al 2004 and references therein). In addition the cell wall sugar composition of the Pucciniomycotina differs from that in the Ustilaginomycotina and Agaricomycotina (Prillinger et al 2002).

Diverse approaches have been used to delimit taxa within the Pucciniomycotina, including studies of ultrastructural, physiological, biochemical and ecological characters. Molecular characters have had a major impact on our understanding of the phylogenetic relationships of Pucciniomycotina. As early as 1985 Gottschalk and Blanz showed that the secondary structure of $5 \mathrm{~S}$ ribosomal RNA in some species of Pucciniomycotina differs from that of some other lineages of Basidiomycota. The pioneering studies of Swann and colleagues (Swann and Taylor 1993, 1995; Swann et al 1999) used nuclear small subunit (nuc-ssu) rDNA sequences to support the monophyly of the Pucciniomycotina and a number of major clades. Other studies have employed a region of about 500-650 bp at the $5^{\prime}$ end of the nuclear large subunit (nuc-lsu) rDNA, containing the highly variable divergent domains D1 and D2 (Hassouna et al 1984) providing resolution for many clades within the
Pucciniomycotina (e.g. Fell et al 2001, Weiß et al 2004, Bauer et al 2006). However D1-D2 sequences have provided only weak support for monophyly of Pucciniomycotina (Begerow et al 1997, Berres et al 1995), or have resolved the group as a paraphyletic assemblage from which the Ustilaginomycotina and Agaricomycotina have been derived (Weiß et al 2004). Nor were analyses of a third gene, that coding for $\beta$ tubulin, able to recover a monophyletic Pucciniomycotina (Begerow et al 2004). Because of the published discrepancies in tree topologies and support values, monophyly for the group has yet to be established conclusively by molecular analyses.

Current major classifications of Pucciniomycotina include those of Kirk et al (2001), Swann et al (2001), Weiß et al (2004) and Bauer et al (2006). The latter three classifications have many similarities (SuPPLEMENTARY TABLE I). However there are also differences between these systems in both resolution and composition of taxa. Kirk et al (2001) divide the Pucciniomycotina (as Urediniomycetes) into five orders and do not include subclasses; thus their classification is quite different from the others.

The goal of the present study is to reassess the higher level systematics of the Pucciniomycotina with combined analyses of nuc-lsu rDNA and nuc-ssu rDNA sequences. Two other studies have included a simultaneous analysis of nuc-lsu and nuc-ssu rDNA sequences of Pucciniomycotina (Lutzoni et al 2004, Bauer et al 2006). However the former was focused on relationships across the Fungi and it included only 14 species of Pucciniomycotina, of which 10 were members of the Pucciniales and the combined analysis in the latter employed only 25 species of Pucciniomycotina and did not cover all major lineages. In the present study we compile and analyze datasets containing new and previously published sequences that represent 174 species from all major groups of Pucciniomycotina. We assess the ability of different rDNA genes and gene regions to recover and support each clade, and we provide an overview of the classes and orders of Pucciniomycotina.

\section{MATERIALS AND METHODS}

This study uses both newly generated sequences and sequences that were retrieved from GenBank from more than 80 studies (Supplementary Table II). Some Pucciniales sequences were generated with the methods described in Aime (2006); sequences of Jola spp. were generated as in Frieders (1997). Descriptions of laboratory methods pertaining to the majority of new sequences produced at Clark University can be found online (SUPPLEMENTARY APPENDIX 1).

The entire data matrix contains 208 operational taxonomic units (OTUs) including six Ascomycota that were 

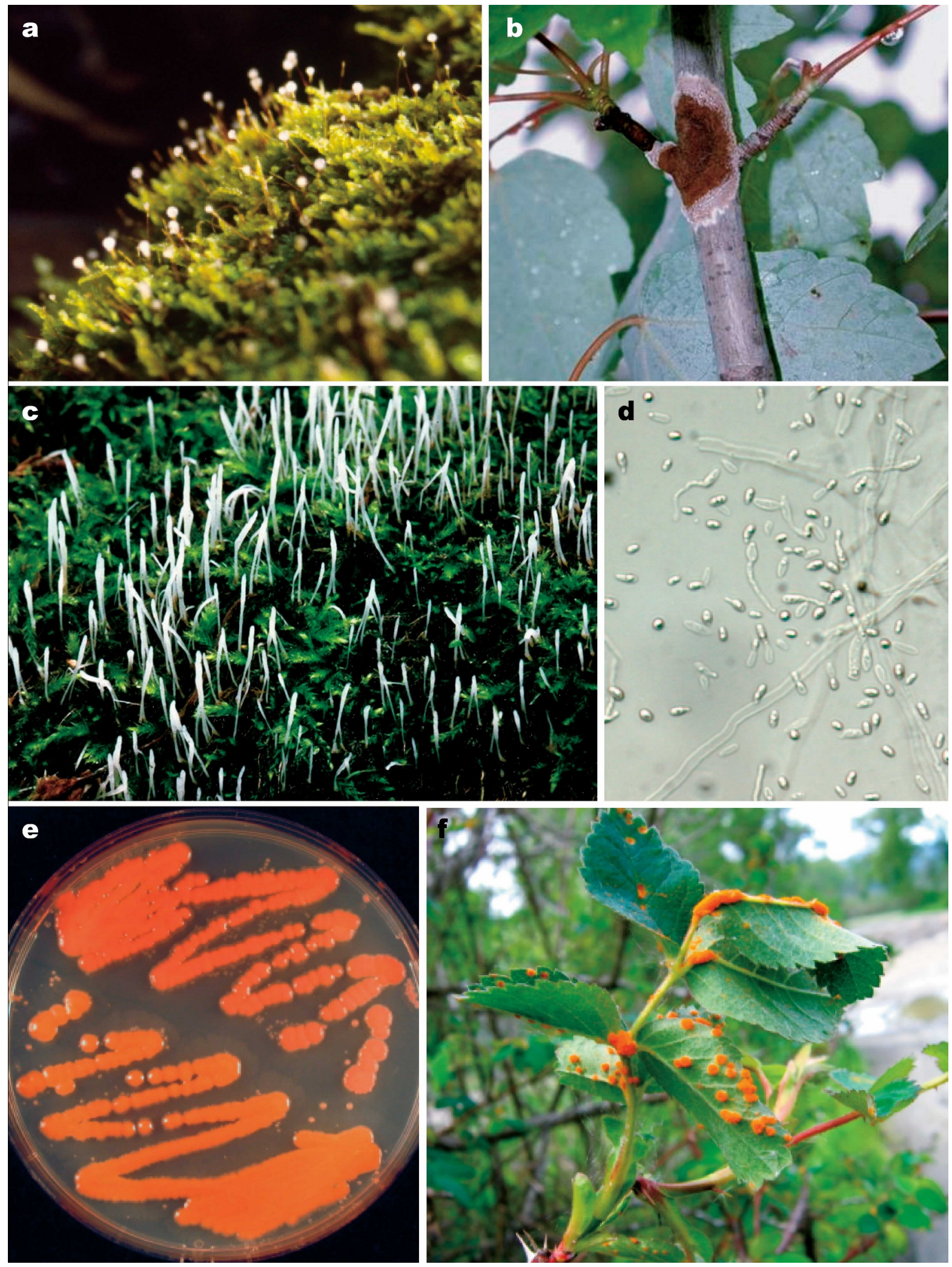

Fig. 1. Representatives of the Pucciniomycotina. a. Jola cf. javensis (Platygloeales) fruiting on Sematophyllum swartzii. b. Septobasidium burtii (Septobasidiales) fungal mat completely covering scale insects. c. Eocronartium muscicola (Platygloeales) fruiting on undetermined moss. d. Yeast and filamentous cells of Sporidiobolus pararoseus (Sporidiobolales). e. Cultures of two Sporidiobolus species in the S. pararoseus clade (Sporidiobolales). f. Phragmidium sp. (Pucciniales) on Rosa rubiginosa. 
used for rooting purposes, nine Ustilaginomycotina, four Agaricomycotina and 189 Pucciniomycotina that represent 174 species (26 species of Pucciniomycotina are represented by two OTUs and one species is represented by three OTUs). One OTU, Septobasidium sp., is represented by a nuc-lsu rDNA sequence deposited as Septobasidium sp. and a nuc-ssu rDNA sequence deposited as Septobasidium canescens. All other OTUs include sequences from the same putative species and where possible from the same collection or isolate (SUPPLEMENTARY TABLE II). Alignments are available from the first and/or last author on request. We performed analyses using two sets of OTUs. Dataset 1 contains the 128 OTUs that have both nuc-lsu and nuc-ssu rDNA, including all the Ascomycota, Ustilaginomycotina and Agaricomycotina, and 109 Pucciniomycotina that include representatives of all the major groups in the classifications of Swann et al (2001), Weiß et al (2004) and Bauer et al (2006) except the Cryptomycocolacomycetes. Dataset 2 contains all 208 OTUs, 74 of which have only nuclsu rDNA, including Cryptomycocolax abnormis (Cryptomycocolacomycetes), and six OTUs that have only the nuc-ssu rDNA. To compare the phylogenetic utility of the short (D1-D2 region only) versus long (D1-D3 region, see SUPPLEMENTARY APPENDIX 1) nuc-lsu rDNA sequences, as well as various combinations of data, we assembled a third dataset (Dataset 3) that contains 20 Pucciniomycotina and two other Basidiomycota that have nuc-lsu rDNA sequences of at least $1117 \mathrm{bp}$ and nuc-ssu rDNA sequences of at least 1667 bp (indicated by an asterisk in SupPLEMENTARY TABLE II). Datasets were analyzed with equally weighted maximum parsimony (MP); Dataset 1 also was analyzed with neighbor joining (NJ) and Bayesian methods. (Details of analytical methods are provided online in SUPPLEMENTARY APPENDIX 1.)

\section{RESULTS AND DISCUSSION}

MP analyses of Dataset 1 recovered 36 trees of 8215 steps $(\mathrm{CI}=0.345, \mathrm{RI}=0.731)$, one of which is depicted (FIG. 2, an expanded version is available in online supplementary materials). MP analyses of Dataset 2 recovered 1000 trees of 9748 steps (CI = 0.310 , RI $=0.729$ ); the strict consensus tree for Dataset 2 is presented (SUPPlementary Fig. 3). Detailed results and discussion of analyses for all three datasets are provided online (SUPPLEMENTARY APPENDIX 2).

This work brings together data from more than 80 studies along with newly generated data to provide the first multigene molecular analyses for all major clades of Pucciniomycotina. The present study strongly supports monophyly of the Pucciniomycotina (FIG. 2). We recover eight major clades containing 18 subclades (SupplementaRY Fig. 3), which most closely correspond to the classification of Bauer et al (2006). All higher taxa of Pucciniomycotina recognized in the present study are supported by bootstrap values of at least $90 \%$ in one or more of our analyses and have Bayesian posterior probabilities of at least 0.98 with the exception of the Sporidiobolales, Agaricostilbomycetes including Spiculogloeales, and the Cryptomycocolacales which is represented by only a single nuc-lsu sequence (SUPPLEMENTARY Fig. 3).

The names of higher taxa used here follow the classification formalized in Bauer et al (2006). The classification of Bauer et al (2006) is different from earlier classifications (SUPPLEMENTARY TABLE I) in that more groups are named and recognized as formal taxa (e.g. Cystobasidiomycetes); groups formerly ranked as subclasses were elevated to the rank of class (e.g. Microbotryomycetes); and higher level names prefixed "Uredinio-" or "Uredin-" have been replaced by names based on Puccinia, the largest genus within the Pucciniomycotina (Kirk et al 2001).

Many of the genera of Pucciniomycotina are not monophyletic, notably anamorphic yeasts such as Rhodotorula and Sporobolomyces (Weiß et al 2004, FIG. 2). One of the obvious obstacles to diagnose Pucciniomycotina taxa is the homoplasious nature of the micromorphological characters available (Bauer and Oberwinkler 1991a, Bauer et al 2006). Ultrastructural characters, for example, structure of spindle pole body or the presence of colacosomes in many Microbotryomycetes (Swann et al 1999) appear promising for delimiting natural groups. However at present the major obstacle to applying meaningful diagnoses to these groups is the dearth of ultrastructural, ecological and life-cycle data for most Pucciniomycotina members.

Descriptions of higher level taxa.-Pucciniomycetes. This is the most speciose class of Pucciniomycotina. We have resolved four orders (Helicobasidiales, Platygloeales s. str., Pucciniales and Septobasidiales). A fifth order, Pachnocybales (Bauer et al 2006), is represented by a single species, Pachnocybe ferruginea (SUPPLEMENTARY Fig. 3) although molecular evidence from other studies places this taxon within the Septobasidiales (Berres et al 1995, Frieders 1997, Henk and Vilgalys 2006). With the exception of $P$. ferruginea, which as a holobasidia-producing saprotroph (Kropp and Corden 1986, Bauer and Oberwinkler 1990) holds an isolated position within the class, and Platygloea disciformis, which may be saprotrophic, all known members are parasitic and produce phragmobasidia or teliospores.

The members of the Helicobasidiales produce a dikaryophase (Helicobasidium) that is parasitic on plant roots and a haplophase (Tuberculina) that is parasitic on rust fungi (Lutz et al 2004b). Species of Tuberculina are capable only of infecting rusts in the haploid stage of development (Thirumalachar 1941) and the host-specificity of some species (Lutz et al 


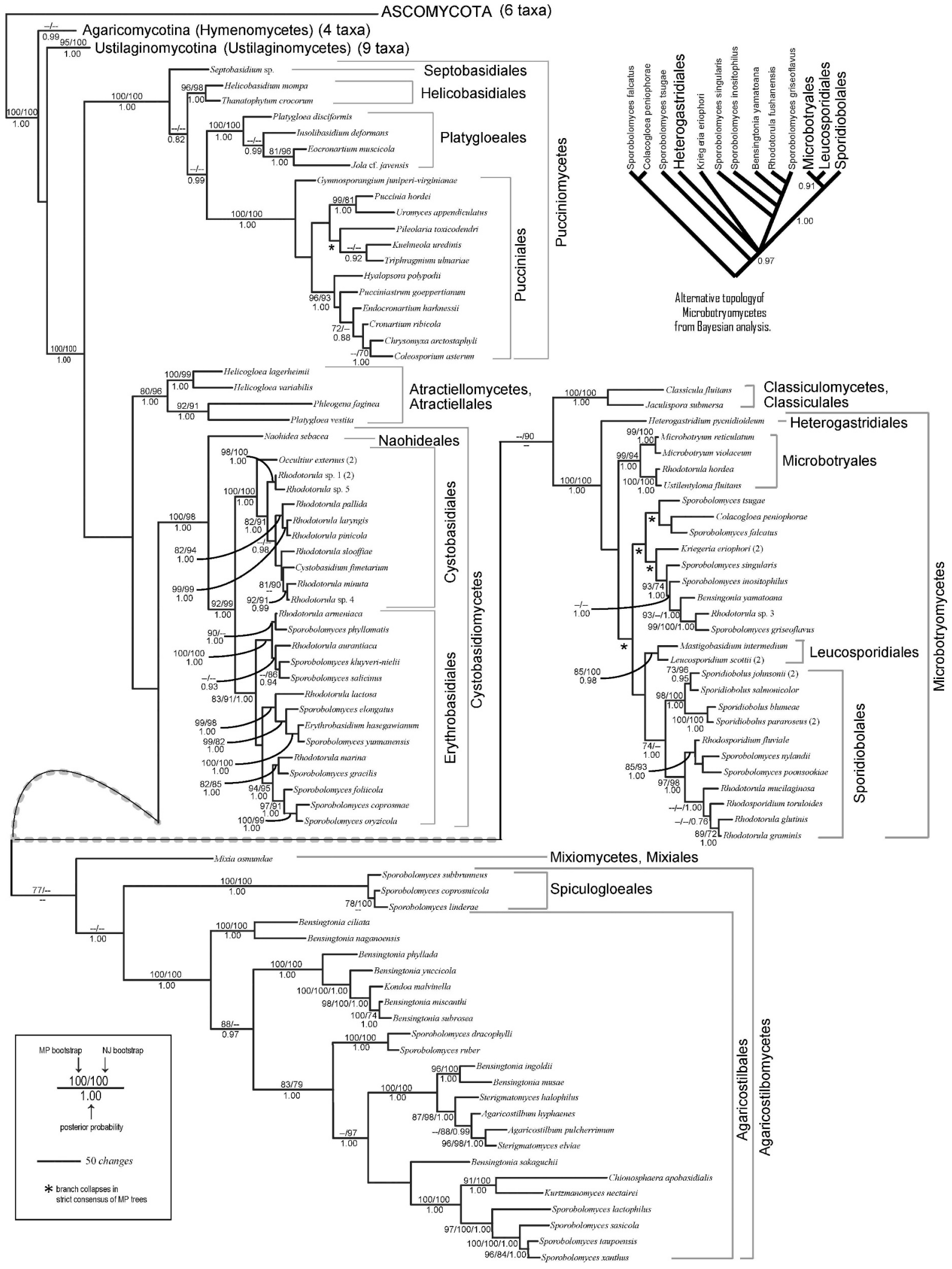

FIG. 2. Phylogenetic relationships in the Pucciniomycotina based on analyses of Dataset 1 (128 OTUs, each with nuc-lsu rDNA and nuc-ssu rDNA sequences). Phylogram representing one of 36 equally most parsimonious trees $(8215$ steps, CI $=$ 0.345 , RI $=0.731)$. Nodes with asterisks collapse in the strict consensus of equally most parsimonious trees. Support values include MP bootstrap frequencies above $70 \%$ (first value, before slash), NJ bootstrap frequencies above $70 \%$ (second value) 
2004a) might make them candidates for biocontrol. Lutz et al (2004c) discuss the confused taxonomic history of Tuberculina. The position of $H$. corticioides could not be confirmed with nuc-ssu data alone (Supplementary Fig. 3).

Until relatively recently all basidiomycetes with transversely septate basidia (termed auricularioid) were classified in the rusts, smuts (Ustilaginales) or Auriculariales (Agaricomycotina). Moore (1990) created the Platygloeales by removing those species that produced simple (rather than dolipore) septal pores from the Auriculariales. The order now is considered to contain mostly phytoparasitic species in the genera Platygloea, Insolibasidium, Herpobasidium, Eocronartium and Jola. These last two genera include species that are parasitic on mosses, produce conidia and develop basidiomata which, in the case of Eocronartium, are clavarioid fruiting bodies that may reach up to $15 \mathrm{~mm}$ tall (Atkinson 1902, Frieders and McLaughlin 2001) (FIG. 1a, c). Fitzpatrick (1918) provides descriptions and illustrations of the life cycle, cytology, host-range and taxonomy of E. muscicola, and the host-parasite interaction is described in Boehm and McLaughlin (1988). The columnar type of fructification (FIG. 1c) similar to that of the rust genus Cronartium led Atkinson (1902) to hypothesize a close relationship between Eocronartium and the Pucciniales, which is supported by molecular analyses (FIG. 2). The unsupported association of Platygloea pustulata with the Septobasidiales (SUPPLEMENTARY FIG. 3) might be an artifact of our supermatrix approach (see SuPPLEMENTARY APPENDIX 2) for which additional gene sampling might be necessary to resolve.

Species of Septobasidiales are unique in that they are parasites of scale insects. This is the second largest order of Pucciniomycotina, with more than 170 described species (Kirk et al 2001), nearly all of which belong to the genus Septobasidium. The principal reference is Couch's 1938 publication "The Genus Septobasidium". These fungi are found as mats of hyphae covering infected scale insects on plants (Fig. 1b). The life cycle (SuPPLEMENTARY Fig. 4) of Septobasidium has been relatively well characterized and includes the only known occurrence of a yeast stage in the Pucciniomycetes. Members of the order live primarily as dikaryons and undergo meiosis within probasidia (Couch 1938, Olive 1943). Auriculoscypha, Coccidiodictyon, Uredinella and Ordonia are the other genera included in the Septobasidiales (Oberwinkler 1989, Henk and Vilgalys 2006).

Pucciniales species are obligate parasites of vascular plants (FIG. 1f) and have developed the most complex life cycles of any Fungi (Cummins and Hiratsuka 2003) (SupPlementaRy Fig. 5). Rusts are phenotypically and genetically plastic organisms with many characters that set them apart from other Basidiomycota including the development of spermogonia, heteroecism and the occurrence of up to six different spore types (Laundon 1973, Hennen and Buriticá 1980, Cummins and Hiratsuka 2003). Approximately 115 (Cummins and Hiratsuka 2003) to 163 (Kirk et al 2001) genera of Pucciniales currently are recognized and family classification remains contentious (Hennen and Buriticá 1980, Ono and Hennen 1983, Kirk et al 2001). Three recent studies of molecular data from nuc-lsu (Maier et al 2003), nuc-ssu (Wingfield et al 2004) and combined nuc rDNA genes (Aime 2006) have provided confirmation for some families (e.g. Melampsoraceae) and highlighted others requiring revision (e.g. Pucciniaceae). The origins of the Pucciniales and their relationship to other Basidiomycota have been a ripe field for conjecture. Many early hypotheses of basidiomycete evolution consider Pucciniales as the most "primitive" Basidiomycota from which all other lineages are derived (e.g. Linder 1940, Savile 1955). Our results confirm other molecular studies (Prillinger et al 2002, Lutzoni et al 2004) that show the Pucciniales as derived from lineages that include insect and nonvascular plant parasites (FIG. 2).

Cystobasidiomycetes. - Our data resolve two orders of Cystobasidiomycetes. A third order, Naohideales, has been proposed (Bauer et al 2006) but it is here represented solely by nuc-lsu sequences of Naohidea sebacea, a mycoparasite (SUPPLEMENTARY FIG. 3). Three mostly monotypic taxa, Sakaguchia (isolated from marine habitats), Cyrenella and Bannoa, cannot be placed into orders with our data. The Cystobasidiales include both anamorphic yeasts and dimorphic yeasts that produce clamp connections and auricularioid basidia without basidiocarps. Genera included in this order are Occultifur (O. internus is a mycoparasite

$\leftarrow$

and Bayesian posterior probabilities above 0.70 (below branch). Outgroup taxa are condensed into a single branch for Ascomycota (six taxa represented); Agaricomycotina (four taxa represented); Ustilaginomycotina (nine taxa represented). Duplicate sequences have been collapsed into a single branch, which are indicated in parentheses after the taxon name, e.g. Occultifer externus (2). The small cladogram depicts the topology of Microbotryomycetidae obtained in Bayesian analyses, with posterior probabilities indicated only for strongly supported nodes that conflict with the MP topology. (An expanded version of FIG. 2 is presented in the online supplementary materials). 
of Dacrymycetales, Bauer et al 2006), Cystobasidium (which like Occultifur produces tremelloid haustorial cells that are indicative of mycoparasitism) and some Rhodotorula spp. (anamorphic yeasts). The Erythrobasidiales include many yeasts currently placed in Rhodotorula pro parte (p.p.) and Sporobolomyces p.p., as well as the monotypic mitosporic yeast Erythrobasidium. Other studies (Sampaio 2004, Bauer et al 2006) support the inclusion of Bannoa within the Erythrobasidiales. No teleomorph has been found in this order.

Atractiellomycetes. - The Atractiellomycetes contain a single order, Atractiellales, originally erected to accommodate gasteroid auricularioid species with simple septa formerly placed in the Auriculariales (Oberwinkler and Bandoni 1982). Walker (1984) and Gottschalk and Blanz (1985) recognized the artificiality of this group, which, as supported by our data, is limited to include the genera Atractiella, Saccoblastia, Hobsonia, Pleurocolla, Helicogloea, Platygloea p.p. and Phleogena. No yeast state is known for these fungi (Swann et al 2001) but some may produce conidia. Atractiella and Phleogena produce stilboid fruitbodies. All members of this class studied thus far possess unique ultrastructural organelles of unknown function termed symplechosomes (Oberwinkler and Bauer 1989, McLaughlin 1990, Bauer and Oberwinkler 1991b).

Agaricostilbomycetes. - Our data strongly support a monophyletic Agaricostilbales that is supported as sister of the Spiculogloeales in Bayesian analyses (FIG. 2). Blanz and Gottschalk (1986) found that structure of the 5S rRNA in Agaricostilbum pulcherrimum, a small gasteroid fungus found worldwide on palms, was unique from all examined basidiomycetes and posited that this taxon held an isolated position within the heterobasidiomycetes. Agaricostilbum is also unusual in that the nuclei divide in the parent cell rather than in the bud cell (Frieders and McLaughlin 1996), and a similar mitotic pattern was found in the closely related Stilbum vulgare but not in the more distantly related (SUPPLEMENTARY FIG. 3) yeast Bensingtonia yuccicola (McLaughlin et al 2004). The yeast phase of the life cycle of $A$. pulcherrimum is illustrated in Frieders and McLaughlin (1996). Other genera placed in the Agaricostilbales include Bensingtonia, Kondoa, Sterigmatomyces, Sporobolomyces p.p., Chionosphaera, Stilbum, Mycogloea p.p. and Kurtzmanomyces. These include gasteroid yeasts with auricularioid basidia (e.g. Agaricostilbum hyphaenes), gasteroid yeasts with holobasidia (e.g. Chionosphaera apobasidialis), and teliospore-forming yeasts (e.g. Kondoa malvinella). Chionosphaera species produce clamps and microscopic stipitate-capitate fruiting structures and are mycophilic, associated with lichens and beetle gallery fungi (Kirschner et al 2001a).

The order Spiculogloeales has been placed within the Agaricostilbomycetes by Bauer et al (2006) and contains Mycogloea p.p., Spiculogloea and some anamorphic Sporobolomyces spp. Characters shared by the teleomorphic species of this order include dimorphism, mycoparasitism and tremelloid haustorial cells subtended by clamp connections (Bandoni 1998). Mycogloea does not appear monophyletic with these data (Supplementary Fig. 3) and additional molecular (combined nuc-lsu and nuc-ssu sequences could not be obtained for any Spiculogloea or Mycogloea species for this study) and taxonomic sampling, including the type species of Mycogloea, are needed to resolve their placement.

Microbotryomycetes. - This group includes mycoparasites, phytopathogens and putative saprotrophs with a diversity of micromorphological characters. Many species contain organelles, termed colacosomes, that are associated with mycoparasitism (Bauer and Oberwinkler 1991a). Four orders are recognized: Heterogastridiales (Oberwinkler et al 1990b), which are mycoparasites and include the aquatic genus Heterogastridium; Leucosporidiales (Sampaio et al 2003), which includes the teliospore-forming yeast Leucosporidium and two other genera, Mastigobasidium and Leucosporidiella; the Sporidiobolales (Sampaio et al 2003), including the genera Rhodotorula p.p., Sporidiobolus (FIG. 1d, e), Sporobolomyces p.p. and Rhodosporidium (a teliospore-forming yeast illustrated in Supplementary Fig. 6); and the Microbotryales (Bauer et al 1997). Members of Microbotryales are teliospore-forming phytopathogens that once were classified within the Ustilaginomycotina and include the genera Bauerago, Fulvisporium, Aurantiosporium, Rhodotorula p.p., Ustilentyloma, Liroa, Microbotryum and Sphacelotheca. Microbotryum violaceum has become an important model organism for co-evolutionary and population genetics studies between pathogens and their hosts (e.g. Antonovics et al 2002).

Additional taxa that belong to this class but could not be assigned to an order are Colacogloea (a monotypic, mycoparasitic genus that possesses colacosomes, Oberwinkler et al 1990a), Kriegeria (a monotypic sedge parasite with an anamorphic yeast stage and unique multiperforate septa, Doubles and McLaughlin 1991, Swann et al 1999), Camptobasidium (a monotypic aquatic hyphomycete associated with decaying leaf litter, Marvanová and Suberkropp 1990), Rhodotorula p.p., Sporobolomyces p.p., Bensingtonia yamatoana and Leucosporidium antarcticum.

Classiculomycetes. - This class contains a single order, the Classiculales, containing aquatic fungi of fresh- 
water habitats (Bauer et al 2003). Classicula fluitans is the teleomorph of the hyphomycete Naiadella fluitans and produces auricularioid basidia and clamp connections. Jaculispora submersa is an aquatic hyphomycete for which no teleomorph has been discovered. Classicula is unique in forming subapically swollen sterigmata (Bauer et al 2003). Classicula fluitans forms tremelloid haustorial cells that were observed to occasionally self-parasitize in culture, which might indicate a mycoparasitic habit for this fungus (Bauer et al 2003).

Cryptomycocolacomycetes. - This class contains a single order, Cryptomycocolacales, represented by the genus Cryptomycocolax, a mycoparasitic fungus that infects ascomycete sclerotia (Oberwinkler and Bauer 1990) and has been placed in the Ustilaginomycotina (Kirk et al 2001). Our study confirms the placement of this clade within the Pucciniomycotina (SuPPLEMENTARY FIG. 3). Cryptomycocolacales species are the only fungi outside the Microbotryomycetes that possess colacosomes, which might indicate a sister group relationship between the two. Cryptomycocolax has a unique mode of basidium development that on the other hand might be indicative of a basal position within the Pucciniomycotina (Oberwinkler and Bauer 1990). Transmission electron microscopy studies of another genus of colacosome-producing mycoparasites, Colacosiphon, indicate that it belongs in the Cryptomycocolacales (Kirschner et al 2001b). Both genera are monotypic.

Mixiomycetes. - This class, containing the Mixiales, is monotypic containing a single fern parasite, Mixia osmundae. Until recently $M$. osmundae was classified within the Ascomycota (Nishida et al 1995) and remains isolated within the Pucciniomycotina with no known close relatives (Swann et al 1999, 2001; FIG. 2). Mixia osmundae is a blastosporic yeast, although it has not been established whether it produces meiospores or mitospores. The hyphae are multinucleate containing few septa (Kramer 1958, Nishida et al 1995, Swann et al 2001).

Incertae sedis. - Reniforma strues was isolated from biofilms in a wastewater treatment plant in West Virginia (Pore and Sorenson 1990). It is a yeast that, unlike any other known basidiomycete, produces kidney-shaped (reniform) somatic cells. Its classification within the Basidiomycota is confirmed with these data, yet its position within the Pucciniomycotina could not be fully resolved with nuc-lsu data alone (Supplementary Fig. 3).

Concluding remarks. - While our results provide the first support for many of the higher level clades of Pucciniomycotina formalized in the classification of
Bauer et al (2006), many nodes, especially along the backbone, still are not resolved. Future molecular systematic studies aimed at filling in missing data in Dataset 2 and targeting additional gene regions for exemplar taxa from all the groups recovered by this study should be the next steps toward recovering a robust phylogenetic hypothesis for these fungi. Additional taxonomic sampling might be necessary before a fully resolved phylogeny for the Pucciniomycotina is attainable. However, excluding the Pucciniales, we have sampled 54 genera, or nearly the entire known generic diversity in the subphylum (Kirk et al 2001). The Pucciniales is often considered one of the best documented groups of fungi. Yet recent estimates indicate that only $10-30 \%$ of their diversity in the neotropics alone has been discovered (Hennen and McCain 1993). Many genera of Pucciniomycotina have been discovered and described only since the 1990 s, often from specialty niches (e.g. beetle galleries, biofilms) or neotropical habitats (e.g. Oberwinkler and Bauer 1990; Oberwinkler et al 1990a, 1990b; Pore and Sorenson 1990; Kirschner et al 2001a, 2001b; Sampaio et al 2003). Furthermore many of these are representative of lineages that are monotypic or problematic with regard to phylogenetic resolution (e.g. Reniforma strues). This would indicate that a tremendous amount of diversity still awaits discovery within this ubiquitous group of fungi.

\section{ACKNOWLEDGMENTS}

The authors thank Conrad Schoch and CBS for providing several cultures and Pat Crane for Pucciniales material used for the generation of sequence data. We thank Rytas Vilgalys and Lisa Bukovnik for access to the DNA sequencing facility at Duke University, Cindy Park for technical support at SBML and Manfred Binder for assistance with Bayesian analyses. This work was supported in part by grants from the National Science Foundation, DEB 0228657, DBI 0320875 and DEB-0090301, Research Coordination Network: A Phylogeny for Kingdom Fungi to M. Blackwell, J.W. Spatafora and J.W. Taylor. Mention of trade names or commercial products in this publication is solely for the purpose of providing specific information and does not imply recommendation or endorsement by the U.S. Department of Agriculture.

\section{LITERATURE CITED}

Aime MC. 2006. Toward resolving family-level relationships in rust fungi (Uredinales). Mycoscience 47:112-122.

Antonovics J, Hood ME, Partain J. 2002. The ecology and genetics of a host-shift: Microbotryum as a model system. Am Nat 160:S40-S53.

Atkinson GF. 1902. Preliminary note on two new genera of basidiomycetes. J Mycol 8:106-107. 
Bandoni RJ. 1998. On some species of Mycogloea. Mycoscience 39:31-36.

Bauer R, Begerow D, Oberwinkler F, Marvanová L. 2003. Classicula: the teleomorph of Naiadella fluitans. Mycologia 95:756-764.

$\longrightarrow,-$ - $\longrightarrow$ Piepenbring M, Berbee ML. 2001. Ustilaginomycetes. In: McLaughlin DJ, McLaughlin EG, Lemke PA, eds. Systematics and evolution. Berlin: Springer, The Mycota VII, Part B: 57-83.

$\longrightarrow$, - Sampaio JP, Weiß M, Oberwinkler F. 2006. The simple-septate basidiomycetes: a synopsis. Mycol Prog 5:41-66.

—, Oberwinkler F. 1990. Meiosis, spindle pole body cycle and taxonomy of the heterobasidiomycete Pachnocybe ferruginea. Plant Syst Evol 172:241-261.

— 1 1991a. The colacosomes: new structures at the host-parasite interface of a mycoparasitic basidiomycete. Bot Acta 104:53-57.

— $-1991 \mathrm{~b}$. The symplechosome: a unique cell organelle of some basidiomycetes. Bot Acta 104:93-97.

— — - Vánky K. 1997. Ultrastructural markers and systematics in smut fungi and allied taxa. Can J Bot 75: 1273-1314.

Begerow D, Bauer R, Oberwinkler F. 1997. Phylogenetic studies on nuclear LSU rDNA sequences of smut fungi and related taxa. Can J Bot 75:2045-2056.

— John B, Oberwinkler F. 2004. Evolutionary relationships among $\beta$-tubulin gene sequences of basidiomycetous fungi. Mycol Res 108:1257-1263.

Berres ME, Szabo LJ, McLaughlin DJ. 1995. Phylogenetic relationships in auriculariaceous basidiomycetes based on 25S ribosomal DNA sequences. Mycologia 87:821840.

Blanz PA, Gottschalk M. 1986. Systematic position of Septobasidium, Graphiola and other basidiomycetes as deduced on the basis of their $5 \mathrm{~S}$ ribosomal RNA nucleotide sequences. Sys Appl Microbiol 8:121-127.

Boehm EWA, McLaughlin DJ. 1988. Eocronartium muscicola: a basidiomycetous moss parasite exploiting gametophytic transfer cells. Can J Bot 66:762-770.

Couch JN. 1938. The genus Septobasidium. Chapel Hill, North Carolina: UNC Press.

Cummins GB, Hiratsuka Y. 2003. Illustrated genera of rust fungi. 3rd ed. St Paul, Minesota: American Phytopathological Society. 225 p.

Doubles JC, McLaughlin DJ. 1991. A new basidiomycetous septal type: the multiperforate septum in Kriegeria eriophori. Am J Bot 78:1542-1548.

Evans H. 1993. Studies on the rust Maravalia cryptostegiae, a potential biological control agent of rubber-vine weed (Cryptostegia grandiflora, Asclepiadaceae: Periplocoideae) in Australia, I: Life-cycle. Mycopathologia 124: 163-174.

Fell JW, Boekhout T, Fonseca A, Sampaio JP. 2001. Basidiomycetous yeasts. In: McLaughlin DJ, McLaughlin EG, Lemke PA, eds. Systematics and evolution. Berlin: Springer-Verlag, The Mycota VII Part B: 3-35.

Fitzpatrick HM. 1918. The life history and parasitism of Eocronartium muscicola. Phytopathology 8:197-218.

Frieders EM. 1997. An integrated approach to understand- ing the moss parasites and their role in basidiomycete evolution [Doctoral thesis]. St Paul: University of Minnesota. $185 \mathrm{p}$.

—, McLaughlin DJ. 2001. The heterobasidiomycete moss parasites Jola and Eocronartium in culture: cytology, ultrastructure and anamorph. Mycol Res 105:734-744.

—_ - 1996. Mitosis in the yeast phase of Agaricostilbum pulcherrimum and its evolutionary significance. Can J Bot 74:1392-1406.

Gottschalk M, Blanz PA. 1985. Untersuchungen an 5S ribosomalen Ribonukleinsäuren als Beitrag zur Klärung von Systematik und Phylogenie der Basidiomyceten. Z Mykol 51:205-243.

Hassouna N, Michot B, Bachellerie J. 1984. The complete nucleotide sequence of mouse $28 \mathrm{~S}$ rRNA. Implications for the process of size increase of the large subunit rRNA in higher eukaryotes. Nucl Acid Res 12:35633583.

Henk DA, Vilgalys R. 2006. Molecular phylogeny suggests a single origin of insect symbiosis in the Urediniomycetidae with support for some relationships within the genus Septobasidium. Am J Bot. (Accepted for publication).

Hennen JF, Buriticá P. 1980. A brief summary of modern rust taxonomic and evolutionary theory. Rept Tottori Mycol Inst 18:243-256.

—, McCain JW. 1993. New species and records of Uredinales from the Neotropics. Mycologia 85:970986.

Kirk PM, Cannon PF, David JC, Stalpers JA. 2001. Dictionary of the fungi. 9th ed. Wallingford, UK: CABI. $655 \mathrm{p}$.

Kirschner R, Begerow D, Oberwinkler F. 2001a. A new Chionosphaera species associated with conifer inhabiting bark beetles. Mycol Res 105:1403-1408.

— genus described for a mycoparasitic fungus. Mycologia 93:634-644.

Kramer CL. 1958. A new genus in the Protomycetaceae. Mycologia 50:916-926.

Kropp BR, Corden ME. 1986. Morphology and taxonomy of Pachnocybe ferruginea. Mycologia 78:334-342.

Laundon GF. 1973. Uredinales. In: Ainsworth CG, Sparrow FK, Sussman AS, eds. The fungi. New York: Academic Press, IVB:247-279.

Linder DH. 1940. Evolution of the basidiomycetes and its relation to the terminology of the basidium. Mycologia 32:419-447.

Lutz M, Bauer R, Begerow D, Oberwinkler F. 2004a. Tuberculina-Helicobasidium: host specificity of the Tuberculina-stage reveals unexpected diversity within the group. Mycologia 96:1316-1329.

—,- - - 2004b. Tuberculina-Thanatophytum/Rhizoctonia crocorum-Helicobasidium: a unique mycoparasitic-phytoparasitic life strategy. Mycol Res 108:227-238.

$\longrightarrow, \longrightarrow, \longrightarrow$, Triebel D. 2004c. Tuberculina: rust relatives attack rusts. Mycologia 96:614-626.

Lutzoni F, Kauff F, Cox CJ, 41 others. 2004. Assembling the 
Fungal Tree of Life: progress, classification and evolution of subcellular traits. Am J Bot 91:1446-1480.

Maier W, Begerow D, Weiß M, Oberwinkler F. 2003. Phylogeny of the rust fungi: an approach using nuclear large subunit ribosomal DNA sequences. Can J Bot 81: 12-23.

Marvanová L, Suberkropp K. 1990. Camptobasidium hydrophilum and its anamorph, Crucella subtilis: a new heterobasidiomycete from streams. Mycologia 82:208217.

McLaughlin DJ. 1990. A new cytoplasmic structure in the basidiomycete Helicogloea: the microscala. Expl Mycol 14:331-338.

—- Hanson Jr RW, Frieders EM, Swann EC, Szabo LJ. 2004. Mitosis in the yeast phase of the basidiomycetes Bensingtonia yuccicola and Stilbum vulgare and its phylogenetic implications. Am J Bot 91:808-815.

Moore RT. 1990. Order Platygloeales ord. nov. Mycotaxon 39:245-248.

Nishida H, Ando K, Ando Y, Hirata A, Sugiyama J. 1995. Mixia osmundae: transfer from the Ascomycota to the Basidiomycota based on evidence from molecules and morphology. Can J Bot 73(1):S660-S666.

Oberwinkler F. 1989. Coccidiodictyon, new genus and Ordonia, two genera in the Septobasidiales. Op Bot 100:185-192.

_, Bandoni RJ. 1982. A taxonomic survey of the gasteroid, auricularioid Heterobasidiomycetes. Can J Bot 60:1726-1750.

_ _ Bauer R. 1989. The systematics of gasteroid, auricularioid Heterobasidiomycetes. Sydowia 41:224256.

- 1990. Cryptomycocolax: a new mycoparasitic heterobasidiomycete. Mycologia 82:671-692.

_ - Bandoni RJ. 1990a. Colacogloea: a new genus in the auricularioid Heterobasidiomycetes. Can J Bot 68:2531-2536.

- -1 - 1990b. Heterogastridiales: a new order of Basidiomycetes. Mycologia 82:48-58.

Olive LS. 1943. Cytology of various basidial types in the genus Septobasidium. Mycologia 35:557-572.

Ono Y, Hennen JF. 1983. Taxonomy of the chaconiaceous genera (Uredinales). Trans Mycol Soc Jap 24: 369-402.
Pore RS, Sorenson WG. 1990. Reniforma strues, a new yeast from wastewater. Mycologia 82:549-553.

Prillinger H, Lopandic K, Schweigkofler W, Deak R, Aarts HJM, Bauer R, Sterflinger K, Kraus GF, Maraz A. 2002. Phylogeny and systematics of the fungi with special reference to the Ascomycota and Basidiomycota. In: Breitenbach M, Crameri R, Lehrer SB, eds., Fungal allergy and pathogenicity. Chem Immunol vol 81. 207295.

Sampaio JP. 2004. Diversity, phylogeny and classification of basidiomycetous yeasts. In: Agerer R, Piepenbring M, Blanz P, eds. Frontiers in Basidiomycote mycology. Eching, Germany: IHW-Verlag. p 49-80.

— Gadanho M, Bauer R, Weiß M. 2003. Taxonomic studies in the Microbotryomycetidae: Leucosporidium golubevii sp. nov., Leucosporidiella gen. nov. and the new orders Leucosporidiales and Sporidiobolales. Mycol Prog 2:53-68.

Savile DBO. 1955. A phylogeny of the Basidiomycetes. Can J Bot 33:60-104.

Swann EC, Frieders EM, McLaughlin DJ. 1999. Microbotryum, Kriegeria and the changing paradigm in basidiomycete classification. Mycologia 91:51-66.

—_, —_- —_- 2001. Urediniomycetes. In: McLaughlin DJ, McLaughlin EG, Lemke PA, eds. Systematics and evolution. Berlin: Springer-Verlag, The Mycota VII Part B: 37-56.

— 18S rRNA gene perspective. Mycologia 85:923-936.

- _ 1995 . Phylogenetic perspectives on basidiomycete systematics: evidence from the 18S rRNA gene. Can J Bot 73:S862-S868.

Thirumalachar MJ. 1941. Tuberculina on Uromyces hobsonii Vize. J Indian Bot Soc 20:107-110.

Walker WF. 1984. 5S rRNA sequences from Atractiellales, and basidiomycetous yeasts and fungi imperfecti. Sys Appl Microbiol 5:352-359.

Weiß M, Bauer R, Begerow D. 2004. Spotlights on heterobasidiomycetes. In: Agerer R, Piepenbring M, Blanz P, eds. Frontiers in Basidiomycote mycology. Eching, Germany: IHW-Verlag. p 7-48.

Wingfield BD, Ericson L, Szaro T, Burdon JJ. 2004. Phylogenetic patterns in the Uredinales. Australas Plant Pathol 33:327-335. 